\title{
In memoriam: Jaakko Hintikka
}

\section{Gila Sher ${ }^{1}$}

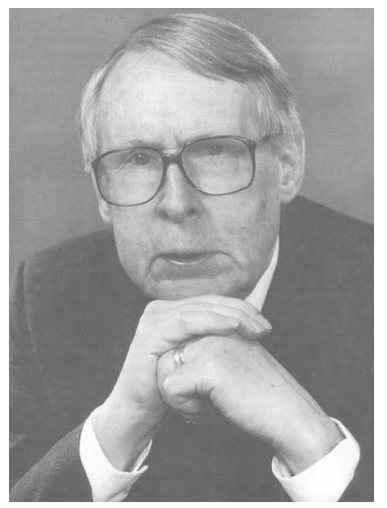

The Editors in Chief of Synthese note with sadness the death of Jaakko Hintikka on August 12, 2015. Hintikka was Synthese's Editor in Chief for almost 40 years (1965 - 2002). He was a charismatic and influential editor who left his stamp on the journal.

Hintikka was a distinguished philosopher and a prolific writer who made important contributions to analytic philosophy. He published close to 40 books and several hundred articles. He was a pioneer in the fields of possible-world semantics, epistemic logic, game-theoretic semantics, branching quantification, IF logic, and more. His contributions spanned a large number of topics from the philosophies of logic, mathematics, science, knowledge, and language to the history of philosophy (Aristotle, Kant, Wittgenstein, and others).

\footnotetext{
$\triangle$ Gila Sher gsher@ucsd.edu

1 University of California, San Diego, San Diego, USA
} 
Hintikka was a recipient of the prestigious Rolf Schock prize of the Royal Swedish Academy of Science in logic and philosophy. Among his seminal books are Knowledge \& Belief (1962), Models for Modalities (1969), Logic, Language-Games \& Information (1973), Investigating Wittgenstein (with Merrill B. Hintikka, 1986), and The Principles of Mathematics Revisited (1998). He will be sorely missed. 